\title{
THE REFRACTION IN BUPHTHALMIA
}

\author{
BY \\ J. Herbert Parsons, \\ LONDON.
}

IT is a well-known fact that, in spite of the great enlargement of the eyeball in buphthalmia, the eye is not nearly so myopic as its abnormal axial elongation would suggest. The chief factors .counteracting axial myopia are :-(1) The flattening of the cornea ;

(2) the flattening of the lens; and (3) the displacement backwards of the lens.

(1) The flattening of the cornea.-The displacement forwards of the cornea, leading to the characteristically deep anterior chamber, is due to stretching of the corneo-scleral junction, so that the peripheral parts of the cornea become usually much thinned relatively to the central part. Owing, however, to the general enlargement of the globe the diameter of the cornea becomes increased, so that the cornea is flattened, and its curvature approximates nearly to that of the sclerotic. Instead of the normal radius of curvature, $7.8 \mathrm{~mm}$., Gros found that the radius is about $11.8 \mathrm{~mm}$.

(2) The flattening of the lens.-O Owing to the stretching of the walls of the globe the ciliary ring, i.e., the circumcorneal scleral ring over the tiliary body, becomes increased in diameter, just as it does in a case of anterior staphyloma. The suspensory ligament is thus abnormally stretched and the lens is flattened, also in exactly the same manner as in a case of anterior staphyloma. As a result the thickness of the lens in the antero-posterior measurement is diminished, and the radii of curvatures of the anterior and posterior surfaces are lengthened. There are no accurate measurements of the lens on recotd, but we shall not be far wrong in taking the average thickness to be reduced from $4 \mathrm{~mm}$. to $3 \mathrm{~mm}$. and the radii of curvature of the anterior and posterior surfaces to be increased from $9.51 \mathrm{~mm}$. and $5.87 \mathrm{~mm}$. to $11 \mathrm{~mm}$. and $7 \mathrm{~mm}$. respectively.

(3) The displacement backwards of the lens.-In most cases there is a slight real displacement backwards of the suspensory ligament relative to its normal attachment to the ciliary body. This is due to the enlargement of the globe and expansion of the scleral ring. Relative to the anterior surface of the cornea there is an enormous displacement backwards. Presuming the thickness of the central part of the cornea to be $1 \mathrm{~mm}$. in both the normal and buphthalmic eye the distances from the anterior surface of the cornea to the anterior surface of the lens are respectively $3 \cdot 78 \mathrm{~mm}$. and $7 \cdot 3 \mathrm{~mm}$. (mean of 10 cases, Gros).

It has occurred to me that it would be interesting to obtain some definite numerical estimates of the effect of these various factors. 
I have therefore calculated the cardinal points of an average buphthalmic eye. The calculations look formidable and involve some tedious arithmetic, but are really quite simple, involving only the repeated application of a few formulae.

The data are set out in the following table, in which the normal measurements are also stated for comparison.

\begin{tabular}{|c|c|c|}
\hline \multicolumn{3}{|r|}{ Buphthalmic Eye. } \\
\hline $\begin{array}{ccc}\text { Cornea } & \ldots & \ldots\end{array}$ & $+7.80 \mathrm{~mm}$ & $+11.8 \mathrm{~mm}$. \\
\hline Ant. surface of lens $\ldots$ & $+9.51 \mathrm{~mm}$ & $+11.0 \mathrm{~mm}$. \\
\hline Post. surface of lens ... & $-5.87 \mathrm{~mm}$. & $-\quad 7.0 \mathrm{~mm}$. \\
\hline \multicolumn{3}{|l|}{ Distance between ant. } \\
\hline surface of cornea and & & \\
\hline i.e., thickness of cornea & & \\
\hline $\begin{array}{ccc}+ \text { depth } & \text { of } & \text { anterior } \\
\text { chamber } & \ldots & \ldots\end{array}$ & $3.78 \mathrm{~mm}$. & $7.3 \mathrm{~mm}$. \\
\hline \multicolumn{2}{|l|}{ Distance between ant. and } & \\
\hline post. surface of lens... & $4.0 \mathrm{~mm}$. & $3.0 \mathrm{~mm}$. \\
\hline \multicolumn{3}{|l|}{ Indices of Refraction :- } \\
\hline Air & $\therefore$ & 1.0000 \\
\hline Cornea, aqueous, and & s... & 1.3465 \\
\hline Total index of refractio & of lens & 1.4545 \\
\hline
\end{tabular}

In the above table and throughout the calculations the usual convention as to signs is used, i.e., measurements in the direction of the incident light are + , those in the opposite direction - .

\section{A. Systems of Two Media}

The formulae for the determination of the focal lengths of systems of two media are

$$
f=\frac{n r}{n^{1}-n} \quad f^{1}=\frac{n^{1} r}{n^{1}-n}
$$

where $f, f^{1}$ are the first and second focal lengths respectively, $n, n^{1}$ the indices of refraction of the first and second media, and $r$ the radius of curvature of the surface.

1. Air and Aqueous Humour.

$$
\begin{aligned}
& f=-\frac{1 \times 11.80}{1.3465-1}=-34.0545 \mathrm{~mm} .(-22.5108 \mathrm{~mm} .) \\
& f^{1}=+\frac{1.3465 \times 11.80}{1,3465-1}=+45.8548 \mathrm{~mm} .(+30.3108 \mathrm{~mm} .)
\end{aligned}
$$

Therefore the anterior focal length of the buphthalmic cornea is $34.0545 \mathrm{~mm}$. in front of the apex of the cornea, and the posterior focal length is $45.8548 \mathrm{~mm}$. behind the apex of the cornea. The corresponding normal measurements are given in brackets. 
2. Aqueous and Anterior Surface of Lens.

$$
\begin{aligned}
& f=-\frac{1.3465 \times 11}{1.4545-1.3465}=-137.1436 \mathrm{~mm} .(-118.5668 \mathrm{~mm} .) \\
& f^{\mathrm{I}}+\frac{1.4545 \times 11}{1.4545-1.3465}=+148.1436 \mathrm{~mm} .(+128.0767 \mathrm{~mm} .)
\end{aligned}
$$

The distance of the first focal point from the apex of the cornea is

$$
7.3-137.1436=-129.8436 \mathrm{~mm} .(-114.7868 \mathrm{~mm} \text {. })
$$

and of the second focal point

$$
7.3+148.1436=+155.4436 \mathrm{~mm} .(+131.8567 \mathrm{~mm} .)
$$

\section{Posterior Surface of Lens and Vitreous.}

$$
\begin{aligned}
& f=-\frac{1.4545 \times(-7)}{1.3465-1.4545}=-94.2731 \mathrm{~mm} .(-79.0545 \mathrm{~mm} .) \\
& f^{x}=+\frac{1.3465 \times 7}{1.4545-1.3465}=+87.2731 \mathrm{~mm} .(+73.1848 \mathrm{~mm} .)
\end{aligned}
$$

The distance of the first focal point from the apex of the cornea is and of the second focal point

$$
7.3+3+87.2731=+97.5731 \mathrm{~mm} .(+80.9648 \mathrm{~mm} .) \text {. }
$$

\section{B. Combination A 2 and A 3}

The formulae for determining the focal lengths $\left(f, f^{1}\right)$ of the system compounded of two other systems whose focal lengths are respectively $f_{1}, f_{1}^{\mathrm{I}}$, and $f_{2}, f_{r_{2}}^{\mathrm{I}}$ are--

$$
\begin{array}{lc}
F_{1} F=\frac{f_{1} f_{1}^{1}}{D} & F_{2}^{\mathrm{I}} F^{\mathrm{x}}=-\frac{f_{2,} f_{2}^{1}}{D} \\
f=\frac{f_{1} f_{2}}{D} & f^{\mathrm{I}}=-\frac{f_{1}^{1} f_{2}^{1}}{D}
\end{array}
$$

where $F_{x} F$ is the distance between the first focus of the first system and the focus of the combined systems, $F_{2}^{x}, F^{x}$ is the distance between the second focus of the second system and the second focus of the combined systems, and D is the distance $\mathrm{F}^{\mathrm{r}}{ }_{1} \mathrm{~F}_{2}$, i.e., between the second focus of the first and the first focus of the second system.

In the buphthalmic eye-

$$
\begin{gathered}
I D=-83.9731-155.4436=-239.4167 \mathrm{~mm} . \\
F_{1}, F-\frac{-137.1436 \times 148.1436}{-239.4167}=+84.8558 \mathrm{~mm} .
\end{gathered}
$$

Therefore the distance of the first focal point from the apex of the cornea

$$
\begin{aligned}
& =-129.8436+84.8558=-44.9878 \mathrm{~mm} \\
\mathrm{~F}_{2}^{\mathrm{x}} \mathrm{F}^{\mathrm{x}} & =\frac{-94.2731 \times 87.2731}{-239.4167}=-34.3624 \mathrm{~mm}
\end{aligned}
$$




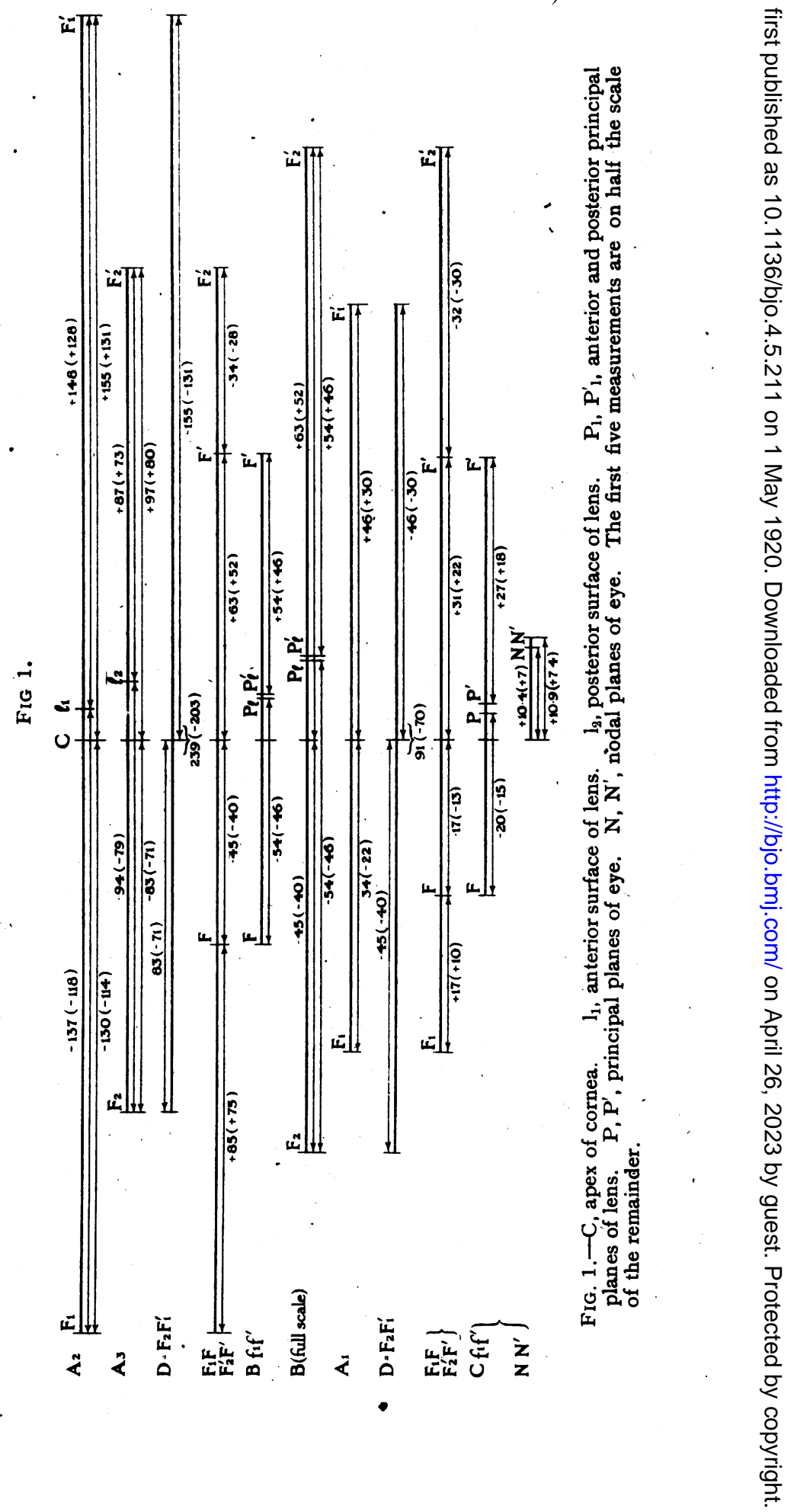


Therefore the distance of the second focal point from the apex of the cornea

$$
\begin{gathered}
=+97.5731-34.3624=+63.2107 \mathrm{~mm} . \\
f=\frac{-137.1436 \times(-94.2731)}{-239.4167}=-54 \mathrm{~mm} .(-46.1438 \mathrm{~mm} .) \\
f^{\prime}=\frac{-148.1436 \times 87.2731}{-239.4167}=+54 \mathrm{~mm} .(+46.1438 \mathrm{~mm} .) \\
\text { C. Combination of } B \text { with } A 1 \\
\mathrm{D}=-44.9878-45.8548=-90.8426 \mathrm{~mm} . \\
\mathrm{F}_{\mathrm{I}} \mathrm{F}=\frac{-34.0545 \times 45.8548}{-90.8426}=+17.1856 \mathrm{~mm} . \\
\mathrm{F}_{2}^{\mathrm{x}} \mathrm{F}^{\mathrm{x}}=\frac{\frac{(54)^{2}}{90.8426} \times-32.0892 \mathrm{~mm} .}{-} \\
f^{=}=\frac{-34.0545 \times(-54)}{-90.8426}=-20.2403 \mathrm{~mm} .(-14.7673 \mathrm{~mm} .) \\
f^{1}=\frac{-45.8548 \times 54}{-90.8426}=+27.2546 \mathrm{~mm} .(+19.8843 \mathrm{~mm} .)
\end{gathered}
$$

The cardinal points of the buphthalmic eye, measured from the apex of the cornea, are therefore :

First focal point $=-34.0545+17.1856=-16.8689 \mathrm{~mm} .(-12.8095 \mathrm{~mm}$.

Second focal point $=+63.2107-32.0822=+31.1215 \mathrm{~mm} .(+22.2119 \mathrm{~mm}$.

First principal point $=-16.8689+20.2403=+3.3714 \mathrm{~mm}(+1.9578 \mathrm{~mm}$.)

Second principal point $=+31.1215-27.2546=+3.8669 \cdot \mathrm{mm} .(+2.3276 \mathrm{~mm}$.

First nodal point $=-16.8689+27.2546=+10.3857 \mathrm{~mm} .(+7.0748 \mathrm{~mm}$.

Second nodal point $=+31.1215-20.2403-+10.8812 \mathrm{~mm} .(+7.446 \mathrm{~mm}$.)

The distance between the princ:pal points $=$ the distance between the nodal points $=0.4955 \mathrm{~mm} . \quad(0.3698 \mathrm{~mm}$.

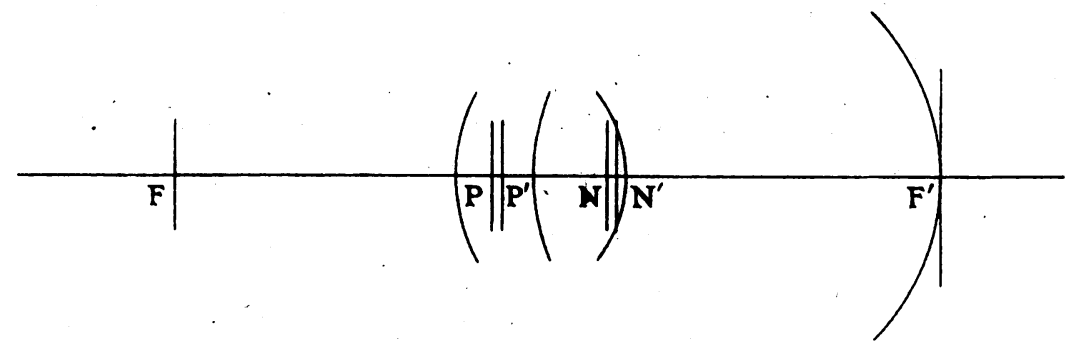

FIG. 2.-Cardinal points of the normal eye.

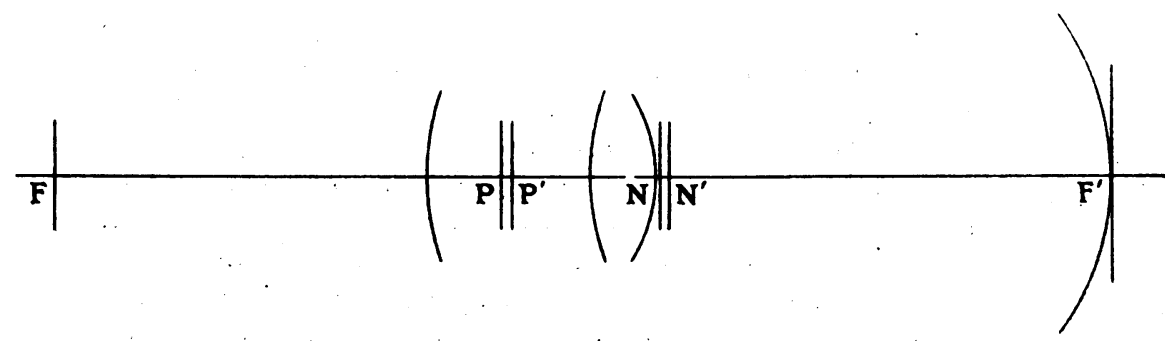

FIG. 3.-Cardinal points of the buphthalmic eye, 
We see therefore that the buphthalmic eye with the average measurements chosen above would have to be $31 \mathrm{~mm}$. long in order that it might' be emmetropic. It is interesting to note that the normal abhakic eye, i.e., the aphakic eye with normal corneal curvature, must also be $31 \mathrm{~mm}$. long in order that parallel incident rays may be focussed upon the retina. Such an eye, before the lens is removed, would have a myopia of $(31-23) \times 3=24 \mathrm{D}$.

E. L. Gros. - Etude sur l'hydrophthalmie ou glaucome infantile. Ferraris' Dioptric Instruments-H.M. Stationery Office, 1919.

\section{AN IMPROVED IRIS PROLAPSE OPERATION FOR GLAUCOMA \\ BY \\ H. Herbert, NOTTINGHAM.}

THIS paper is supplementary to the somewhat cursory description of work done in India, published in the Trans. Ophthal. Soc. U.K., Vol. XXXIX (1919), p. 218. To make the subject fully intelligible to those who do not see the Transactions, an outline of salient facts is included here.

The facts and arguments collected below form a reasoned plea for a fairly general utilization of the prolapse operation in this country. The appeal is timely, since many surgeons have been driven back to iridectomy by late infections following sclerectomies. This is surely a retrograde step, an unwarranted confession of failure in the professed filtration methods as a whole. Extremely valuable though iridectomy has been, it is for ever discredited as a satisfying future treatment by the fact that it fails most often (1) when most perfectly performed, and (2) where least is asked of it, in the more chronic simple glaucomas. One can never again rest content to ignore the urgent call for clinical and pathological research to explain these iridectomy results fully, and to explore the possibilities contained in them.

Method.-A purely subconjunctival sclero-corneal incision, about $6 \mathrm{~mm}$. long, is made above, close to the limbus, with $1 \mathrm{~mm}$. Graefe knife. The only conjunctival puncture is $3 \mathrm{~mm}$. away from the limbus; from this point the conjunctiva is slid on the point of the knife. The puncture is enlarged a little when withdrawing the knife. It is quite easy to avoid wounding the conjunctiva at the counter-puncture, by beginning short sawing movements as soon as the point of the knife is seen perforating the sclera. Through this section a wide fold of iris is drawn up under the conjunctiva (see later), where it is transfixed and incised by the same narrow 